\title{
Aplicación de TBL en el aula
}

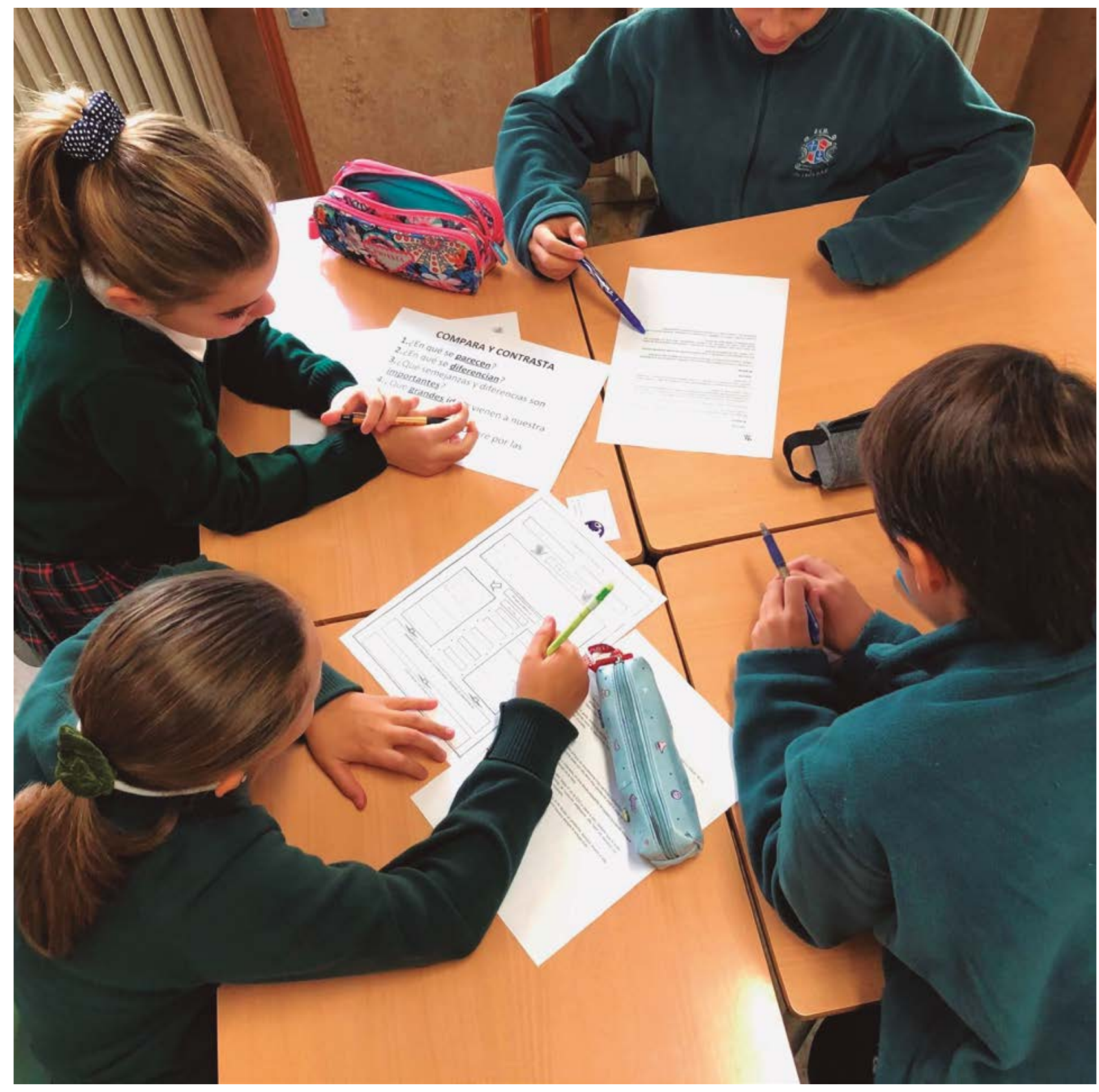

La sociedad de la inmediatez, la incertidumbre, la falta de imaginación y la exposición constante a información por parte de nuestro alumnado hacen necesaria una

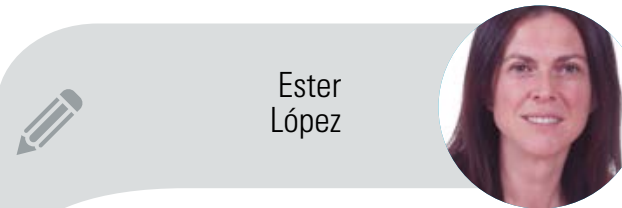

Colegio Bienaventurada Virgen María - Irlandesas El Soto ester.lopez@irlandesaselsoto.net metodología en la que enseñemos a pensar. 
Esta metodología, creada por Robert Swartz ("Hay que enseñar a pensar más que a memorizar") ayudará a crear estrategias en la forma de pensar del alumnado para poder aplicar en cualquier ámbito de su vida. Lo ideal es realizarlo basándose en el trabajo cooperativo (portavoz, coordinador, supervisor, moderador...) y así, también ayudaremos a desarrollar todas las competencias y habilidades en esta forma de trabajar.

El TBL es una metodología compatible con cualquier metodología actual y va a ayudarnos a desarrollar la inteligencia emocional, el trabajo cooperativo, proyectos de investigación y comprensión, uso de tecnologías y fiabilidad de las fuentes, experiencias vivenciales..., desde la diversidad y en cualquier área. El papel del profesor es de guía y el alumno será el protagonista del proceso de aprendizaje.

Según esta metodología, usaremos diferentes estrategias de pensamiento con la finalidad de desarrollar una destreza en todos los tipos de pensamiento. Estos, se diferencian en 4 bloques:
Basar nuestra forma de enseñar en el TBL significa que estas estrategias se convertirán en destrezas, por lo que es importante trabajar con ellas desde Educación Infantil hasta el final de la etapa escolar teniendo en cuenta los diferentes niveles de maduración y haciendo las sesiones apropiadas para cada nivel.

Las sesiones que desarrollarán este tipo de metodología tendrán dos objetivos:

1. Estará basado en el objetivo curricular del área.

2. Será el objetivo de pensamiento.

Todas estas estrategias de pensamiento serán guiadas a través de un mapa de pensamiento. Cada una de las estrategias sigue una serie de pasos determinados que se plasmarán en un organizador gráfico. A través de esos pasos y mientras se desarrolla la estrategia, irán surgiendo ideas para después realizar una conclusión. Esta conclusión, en cursos superiores, se plasmará en un mapa de escritura y en una escalera de metacognición.

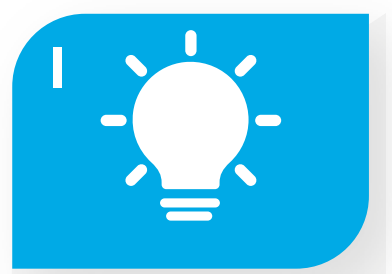

Generar ideas

1. Ideas creativas

A. Multiplicidad de ideas

B. Ideas varias

C. Ideas nuevas

\section{Composición D. Analogía / metáfora}

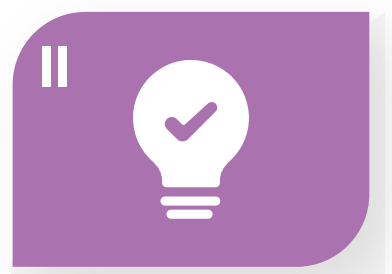

Clarificar ideas

3. Analizar ideas

A. Comparar / contrastar

B. Clasificar / definir

C. Las partes y el todo

D. Secuenciar

4. Analizar argumentos E. Encontrar razones / conclusiones

F. Descubrir asunciones

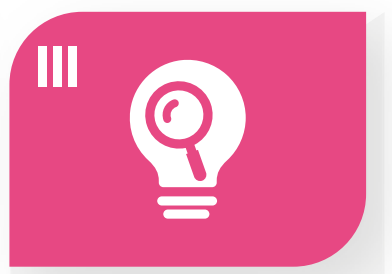

Evaluar la razonabilidad de las ideas

1. Evaluar información básica

A. Exactitud en la observación

B. Fiabilidad de las fuentes

2. Inferencias

C. Uso de la evidencia

1. Explicación causal

2. Predicción

3. Generalización

4. Razonamiento por analogía

D. Deducción

5. Razonamiento condicional

(si... entonces...)

6. Razonamiento de categoría

(algunos... todos...)

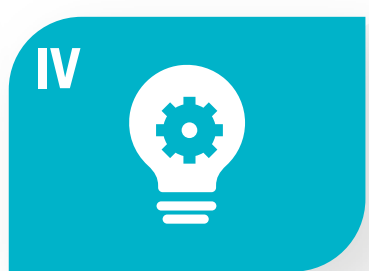

Tareas complejas de pensamiento

1. Toma de decisiones

2. Resolución de problemas 


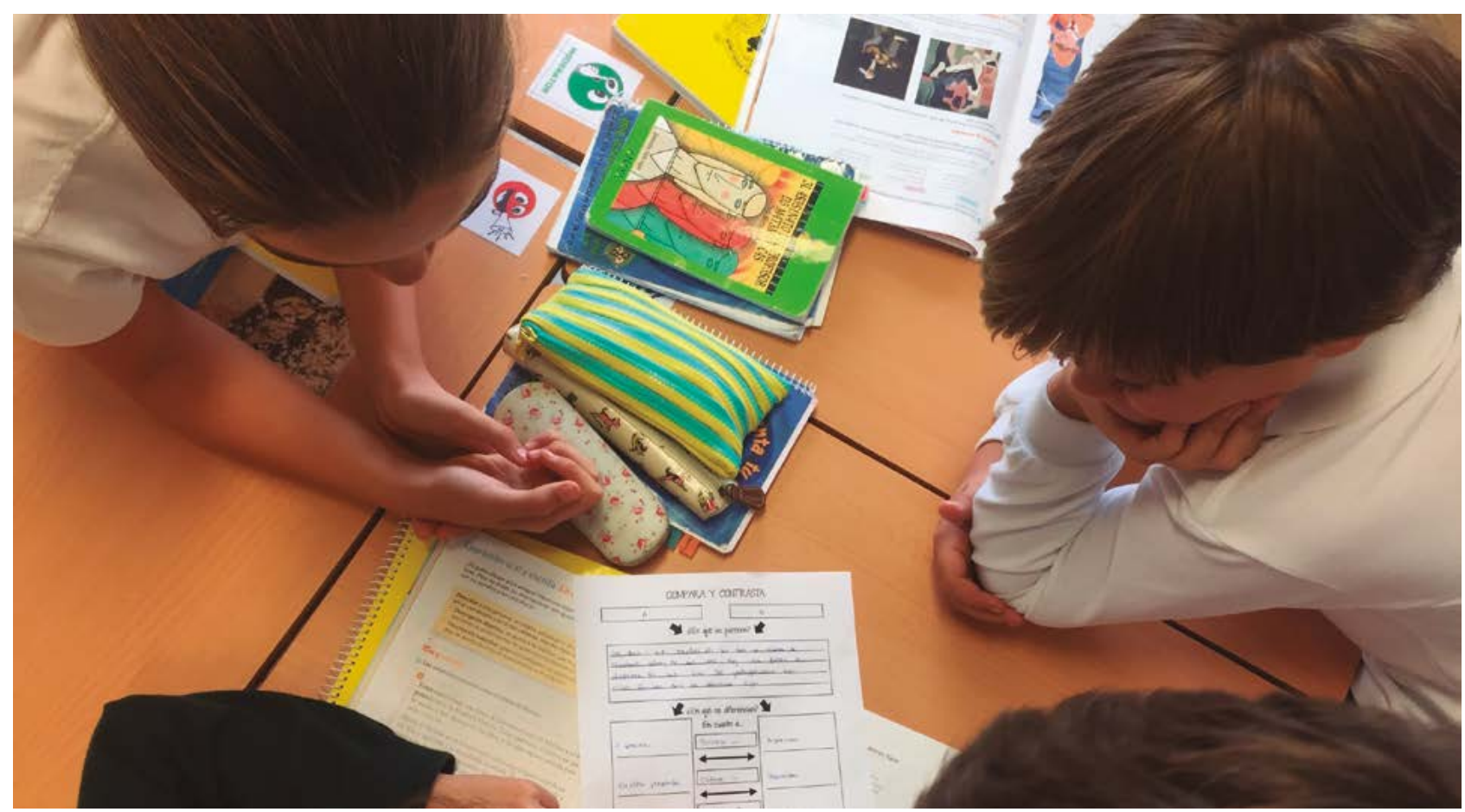

El aprendizaje activo de
nuestro alumnado mejora
con la metodología TBL: los
conceplos y los objelivos
curriculares marcados se
consiguen con mejores
resultados

El mapa de pensamiento es una serie de preguntas que guiarán la estrategia. Cada una de las estrategias tiene su propio mapa y dependerá del nivel educativo en el que estemos trabajando. Lo ideal es que el alumnado realice los mapas de pensamiento en cartulinas, con las preguntas correspondientes a cada estrategia y que así se puedan ir colgando en el aula para que estén visibles durante todo el curso.

La respuesta a cada pregunta la escribiremos en el organizador gráfico. En niveles inferiores, podemos hacer un mural grande e ir respondiendo a las preguntas oralmente para que el profesor vaya escribiéndolas en el organizador con las ideas que van surgiendo del alumnado. En niveles superiores, lo realizarán en un organizador gráfico por grupo.

Después de cada paso, pregunta y respuesta, lo pondremos en común para que todos los grupos escriban y comple- ten su organizador con las ideas de sus compañeros. El portavoz de cada grupo cooperativo tendrá la función de compartir las ideas de su grupo con toda la clase, a medida que la sesión vaya avanzando. Compartir las ideas va a ayudar a todos los estudiantes a incorporar nuevas ideas en la estrategia de pensamiento.

El profesor irá guiando en estas respuestas que ponemos en común para llevarlos, más adelante, al objetivo curricular que se proponga en la lección de infusión (programación de las sesiones de la estrategia).

Es importante que, a lo largo de las sesiones TBL, utilicemos el lenguaje adecuado y todos estos conceptos para que se vayan familiarizando con la terminología. El objetivo es enseñarles a pensar, por lo que no debemos dejar de guiar el aprendizaje haciendo preguntas abiertas y de extensión (de clarificación, elaboración o preguntas de desafío) durante todo el proceso.

Cada estrategia de pensamiento, a partir de los cursos superiores de Primaria, se pueden traducir en mapas de escritura en los que trabajaremos los textos argumentativos, expositivos, instructivos... y desarrollaremos la expresión escrita.

Antes de finalizar la sesión es fundamental ayudar al alumnado a pensar sobre su propio pensamiento (metacognición) 


\section{Las partes y el todo}

\section{EL OBJETO:}

\section{LAS PARTES}

para que puedan llegar a conclusiones sobre cómo han realizado la estrategia mediante una escalera de metacognición (común para todas las estrategias):

त Ser consciente del tipo de estrategia utilizado.

入 Conocimiento de dicha estrategia durante el proceso.

7 Evaluación reflexiva de la estrategia utilizada (efectividad de la misma).

$\boldsymbol{\lambda}$ Utilización de otro tipo de estrategia para el concepto trabajado.

El fin de la metacognición es conducir al alumnado a aprender de una forma más autónoma en cada nueva situación en la que tengan que llevar a cabo una estrategia de pensamiento.

Hagamos a nuestro alumnado diestro en el pensamiento y en la capacidad de desarrollar habilidades para el futuro. Que sepan trabajar y pensar de forma cooperativa. Que sepan exponer sus ideas con una fundamentación y razonamiento lógico. Que sepan traducir sus pensamientos y objetivos en argumentaciones y acciones eficaces. Todos estos valores se convierten en imprescindibles ante un futuro incierto, del que no sabemos para qué estamos preparando a la sociedad del futuro.

La evaluación se puede realizar desde diferentes perspectivas: autoevaluación, coevaluación y heteroevaluación (grupal e individual).

La evaluación, después de las sesiones TBL, es más eficaz que la tradicional. Los exámenes o pruebas tradicionales, normalmente, se basan en recordar lo aprendido. Con esta metodología el alum-

\section{HEMOS HABLADO DE}

\section{Metodología; enseñar a pensar; estrategias; destrezas; metacognición.}

Este artículo fue solicitado por PADRES Y MAESTROS en septiembre de 2020, revisado y aceptado en febrero de 2021.

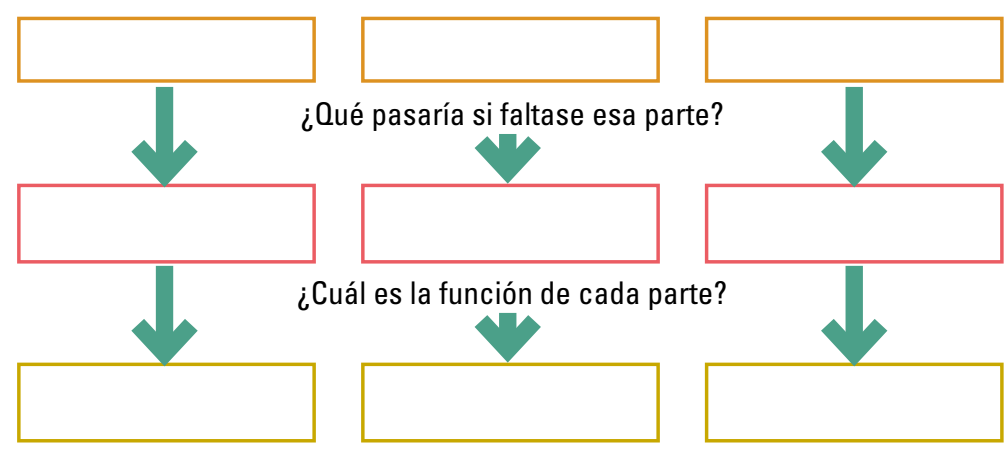

¿Cómo funcionan juntas las partes para hacer que todo sea lo que es?

nado reproduce el proceso y la estrategia relacionando la información adquirida y demostrando una verdadera comprensión de los conceptos.

Durante estos años de aplicación, he podido comprobar que el aprendizaje activo mejora con esta metodología, los conceptos son asimilados mucho mejor y los objetivos curriculares marcados se consiguen con mejores resultados.

A pesar de los libros y artículos que me he leído, lo que me convenció realmente fue la formación que recibí y realizar el coaching por parte del mismísimo Robert Swartz para obtener el título de "experta en TBL" y la motivación encontrada en el alumnado realizando este tipo de metodología •

\section{DRRr SABER MẤS}

BBVA Aprendemos Juntos. (2018). Robert Swartz: aprendiendo a pensar mejor. Recuperado de: https://aprendemosjuntos. elpais.com/ especial/ensenar-a-pensar-mejor-robert-swartzl

SwARTz, R. (2019). Pensar para aprender: Cómo transformar el aprendizaje en el aula con el TBL. España: Ediciones SM.

SwARTZ, R. (2019). Pensar para aprender en el aula: Lecciones de aprendizaje basado en el pensamiento (TBL) para Educación Primaria. España: Ediciones SM.

SwARTZ, R. El Blog Oficial de Robert Swartz y Thinking Based Learning [blog]. Recuperado de https://robertswartz.org 